\title{
Issues in Doctoral Studies - Forty Years of Journal Discussion: Where have we been and where are we going?
}

\author{
Michael Jones \\ University of Wollongong, Wollongong, NSW, Australia
}

mjones@uow.edu.au

\begin{abstract}
The scrutiny of doctoral studies as a field of academic research and discussion is relatively new, but it is growing quickly. An understanding of what has been said and why is important because it helps us to comprehend recurring themes and issues. This paper examines 995 papers written on issues of doctoral studies through the years 1971 to 2012. Thematic analysis of these papers presents six central themes through which the management and training of doctoral students has been embodied. These six themes include teaching, doctoral program design, writing and research, employment and career, student-supervisor relationship, and the doctoral student experience. This paper expands on this analysis to unveil the roads we have travelled and the paths we are yet to travel down, and importantly the issues which have not been fully explored, and thus - continuing with this metaphor - remain uncharted.
\end{abstract}

Keywords: Doctoral Program Design, Doctoral student experience, Employment \& Career, student-supervisor relationship, Teaching, Writing and Research.

\section{Introduction}

The doctoral degree is perceived by most academic institutions as the pinnacle of educational achievement (Jairam \& Kahl Jr., 2012; Park, 2005). Notable exceptions to this are advanced doctoral degrees like the Habilitation in Poland and the Privatdozent (Docent) degree in Germany and Switzerland. The training and development of doctoral students is an important function of most tertiary educational institutions. Through doctoral education future faculty are trained, and future leaders of commerce and industry are developed (Millett \& Nettles, 2006). Doctoral students: "[create] the new ideas and knowledge upon which future educational activities can be built, sustained and nourished" (Davis, Evans, \& Hickey, 2006, p. 236). Further, doctorial students are the mediators of idea exchange between universities and business (Thune, 2009).

The educational institution plays a large role in shaping the doctoral student into the future academic or practitioner. However, it is the

Material published as part of this publication, either on-line or in print, is copyrighted by the Informing Science Institute. Permission to make digital or paper copy of part or all of these works for personal or classroom use is granted without fee provided that the copies are not made or distributed for profit or commercial advantage AND that copies 1) bear this notice in full and 2) give the full citation on the first page. It is permissible to abstract these works so long as credit is given. To copy in all other cases or to republish or to post on a server or to redistribute to lists requires specific permission and payment of a fee. Contact Publisher@InformingScience.org to request redistribution permission. doctoral supervisor who is fundamental to this transition and in refining the future roles that these people will play in society and academia (Barnes, Williams, \& Archer, 2010; Halse \& Malfroy, 2010; McAlpine \& Amundsen, 2012). To ensure greater success in the doctoral graduate process, supervisors and institutions must have an understanding of the issues which arise through this task. 
Problems and issues can occur in many areas of the doctoral journey. Four issues are commonly discussed in the literature; these are attrition, supervisor relationship, supervisor quality, and social isolation.

Research finds that attrition rates for doctoral students range from 33\% to 70\% (Gardner \& Gopaul, 2012; Ivankova \& Stick, 2007; Jiranek, 2010; Kim \& Otts, 2010) with many students leaving in their first year (Jairam \& Kahl Jr, 2012; Lott, Gardner, \& Powers, 2010). Stress and isolation are found to be prime contributors to the phenomenon of attrition (Jairam \& $\mathrm{Kahl} \mathrm{Jr}$, 2012). Socialization and a positive supervisor relationship have been shown to drive retention and student success (Ali \& Kohun, 2007; Barnes, 2010; Gardner, 2008). As Ali and Kohun (2007, p.42) discuss, "In doctoral studies, encouraging social contact and providing social support goes a long way in minimizing the effect that social isolation has on students"

As discussed above, the supervisor bears a fundamental responsibility in ensuring doctoral success, so it is not surprising to see that the quality of supervisors and advisors and their relationship with students is a commonly discussed issue in doctoral education literature. Barnes and Austin find these to be "exceedingly vexing problems" $(2009,298)$. Good advising relationships assist students with socialization and cultural indoctrination and better equip students with the tools they need to survive and prosper (Ampaw \& Jaeger, 2012; Barnes et al., 2010; Felt, Igelsböck, Schikowitz, \& Völker, 2012; Halse, 2011).

The preceding issues of attrition and supervisor quality and relationship each point to the importance of the fourth issue, which is socialization, and its counter force - isolation. The task of research and writing a dissertation is, by design, a solitary journey which is "accomplished through the socially (and often physically) isolated context of field research, experienced and celebrated as a personal rite of passage" (Delamont, Atkinson, \& Parry, 1997, p. 327). However, the implicit isolation which accompanies doctoral studies must be balanced with peer, supervisor, and institutional socialization, otherwise isolation can degenerate into alienation, and thus result in attrition (Gardner, 2010).

These issues and others will be discussed in this paper. The discussion which follows is based on a thematic analysis of 995 papers on doctoral issues which have been published in 45 of the most prominent journals in this sector (a complete list of these journals and the number of papers from each which have been included in this analysis are included in the Appendix at the end of the paper). This research is unique as no other analysis of this body of literature has been conducted, nor has any literature review previously brought together this complete volume of work. This research is important because it provides the reader a concise, yet thorough, snapshot of the work that has progressed in doctoral studies over the last 40 years.

The next section will discuss the methodological approach used in this paper. This will be followed by a section which presents the analysis and findings. Following this will be a discussion and then a conclusion.

\section{Research Method}

Thematic analysis is a commonly adopted, yet infrequently attributed, method for encoding qualitative data (Boyatzis, 1998; Braun \& Clarke, 2006). In employing the method, the researcher searches for 'themes' by carefully "reading and re-reading" the data (Rice \& Ezzy, 1999, p. 258). Themes accumulate as data are coded to conform to identifying patterns with similar meaning. The resulting analysis captures rich detail through which an interpretation of the underlying data is possible (Yardley \& Marks, 2004). Thematic analysis can adopt either an inductive or deductive approach. The former can be seen as a bottom-up or data-driven approach where the data drives the selection of codes and themes, as such findings are grounded in the data (Braun \& Clarke, 2006). The latter approach utilizes a top-down or a theoretically prescriptive perspective. 
This approach forces the coding of data into a preconceived theoretical framework. The former, the inductive approach, has been selected for this research as it's more emergent style better suits the constructive epistemology of the research project.

Five steps were used to analyze the data. These are discussed below.

\section{Step 1 - Scoping}

In the first step, a scoping process, was used to preference data collection. 48 journal articles were read from the International Journal of Doctoral Studies covering the period 2006 to 2012. References from these papers were assessed to determine the range of journals which publish articles based on doctoral studies, issues, and education. 60 journals were identified. After validation of access and verification of content, this was reduced to 45 journals to be included in the literature search.

\section{Step 2 - Literature Search}

In the second step, the valid journals were searched using the databases Eric, Proquest, or Scopus depending on which database gave the larger result. The search was based on the search terms shown in Table 1. This strategy was designed to ensure that the selection of papers for analysis would be related to the target theme of doctoral studies, issues, and education.

Table 1: Search criteria and results

\begin{tabular}{|c|c|c|c|c|c|}
\hline Key Word Search Term: & PhD & Doctorate & Doctoral & Thesis & Dissertation \\
\hline Result & 271 & 271 & 891 & 170 & 118 \\
\hline
\end{tabular}

After further verification and validation a final list of 995 papers was prepared for analysis.

\section{Step 3 - Preparation for Coding}

In the third step, a cross-section of the papers $(20 \%)$ was selected to gain an understanding of which themes existed so that the next step (comprehensive coding) could be approached in a consistent and repeatable manner. In executing this step each of the 199 randomly selected articles was read thoroughly to create a rigorous coding structure. Codes were created using Nvivo 10.0 (www.qsrinternational.com). To ensure that coded documents remained valid as the coding structure emerged a process of constant comparison (Jones \& Alony, 2011) was adopted in both adhoc and post-hoc modes - this meant that previously coded documents were recoded whenever the coding structure changed.

\section{Step 4 - Comprehensive Coding}

After completing Step 3, it became apparent that the entire paper did not need to be analyzed to maintain an accurate approach to coding. In most cases, coding was limited to the paper's abstract, conclusion, title, and keywords, as this was found to accurately represent the content of the entire document for the purpose of coding its content. In Step 4, coding continued using this abbreviated approach until all documents were coded.

\section{Step 5 - Thematic Analysis}

The final step involved ensuring that the themes represented the content of the body of papers and that thematic titles were descriptive and meaningful. On completion of this step a thematic map was produced - see Figure 1 in the 'Analysis and findings' section below. 


\section{Limitations of Thematic Analysis}

Thematic analysis is not analysis per se. Analysis is limited to the collection of representative codes to which a descriptive label is attached. Analytical meaning is inferred or unpacked through discussion and recontextualization (Braun \& Clarke, 2006). The resulting narrative is strengthened by the thematic analysis, especially through the utilization of rich detail or 'thick description' (Geertz, 1973).

\section{Analysis and Findings}

Analysis of the 995 journal articles found that discussion in doctoral studies journals over the forty years centralized on six major themes. Figure 1 presents these themes and each will be discussed in greater detail below. After this discussion additional analysis will be presented based on chronological and geographical dispersion. Figure 2 presents the distribution of discussion by issue.

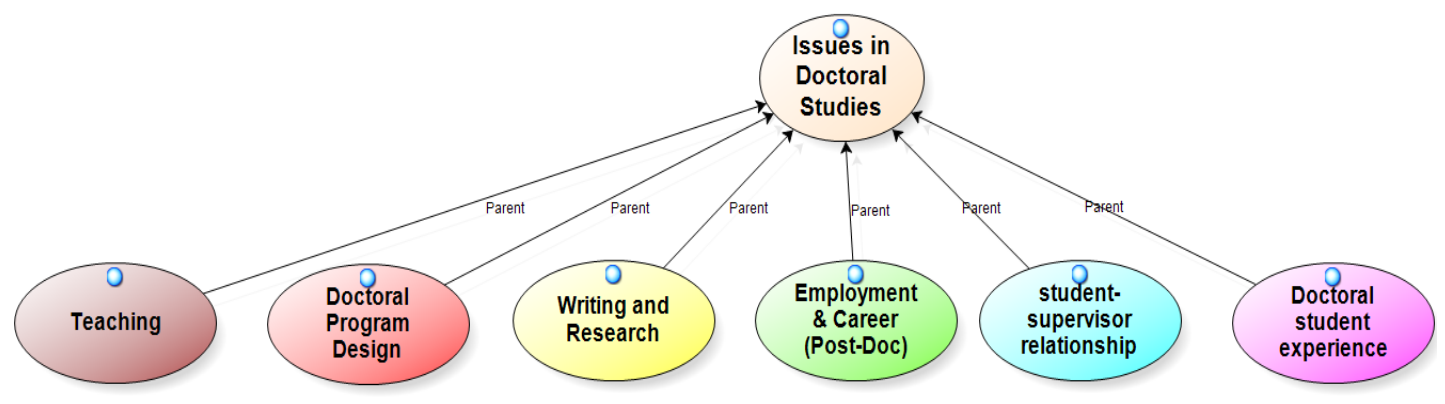

Figure 1: The six major themes comprising issues in doctoral studies

This figure, and those which follow, are products of the software used for analysis (Nvivo). Analytical information, e.g., the blue circles and the 'Parent' designator, are embedded in the figure, they cannot be removed. The former indicates that the subject is a thematic node while the latter indicates that the node has a hierarchal relationship.

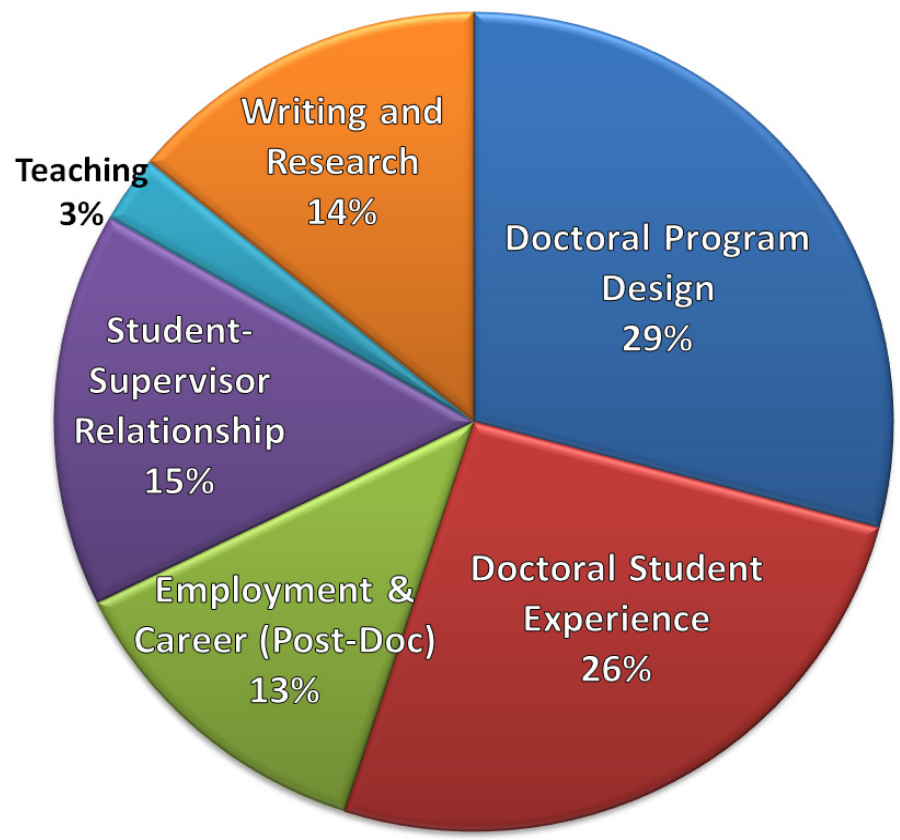

Figure 2: Distribution of discussion by issue 


\section{Issues around Teaching}

Teaching accounts for a very small proportion of the overall discussion on Doctoral Studies, only $3 \%$ of the overall number of issues discussed. Figure 3 shows that the discussion is broken into two areas of concern - Preparation for teaching and the Importance of teaching - and these are evenly split with regard to presentation of issues.

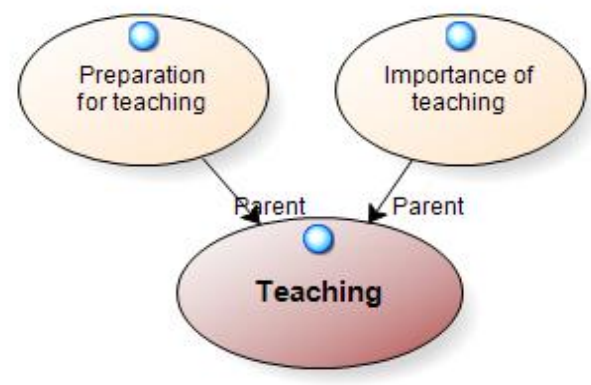

Figure 3: Issues around teaching

\section{Preparation for teaching}

The journal discussion around preparation for teaching is largely based on the evident lack of the development of teaching abilities for doctoral students. Institutions expend resources which focus on completion times and retention and which prepare students for the research side of the academic career. However, very little emphasis is placed on preparing our burgeoning academics for the other side of the post-doctoral (and even co-doctoral) experience which is to teach students. A quote from Gaff \& Pruitt-Logan (1998, p. 77) helps to clarify the issue:

Let's face it. We have never really prepared graduate students to become college professors. Traditional doctoral study is designed to give graduate students the capacity to conduct original research. This is a necessary but insufficient condition for faculty success. After all, most faculty members manage a wide range of roles. Most teach and advise undergraduates, and many also teach graduate students. Many graduate students, however, acquire no experience in the complex tasks of teaching.

\section{Importance of teaching}

This complementary issue presents calls for teaching to become a formal part of the doctorate and generally to be acknowledged as a serious component in the training, socialization and, employment of doctoral students. Jepsen, Varhegyi, and Edwards (2012) argue that the relative importance of teaching is treated ambiguously. While there is clear rhetoric professing the absolute importance of teaching to the individual and the institution, this is often overshadowed by the reality of academic rankings, promotion scorecards, and university funding schemes, all of which seem to value research over teaching as the measure of worth and value, especially at research intensive universities.

\section{Issues around doctoral program design}

Discussions around issues of 'doctoral program design' dominate the publications in this area (Figure 2). The ten topic areas shown in Figure 4 receive relatively similar attention, with a little more concern over 'professional doctorates'. The more prominent of these ten topics will be addressed briefly below. 


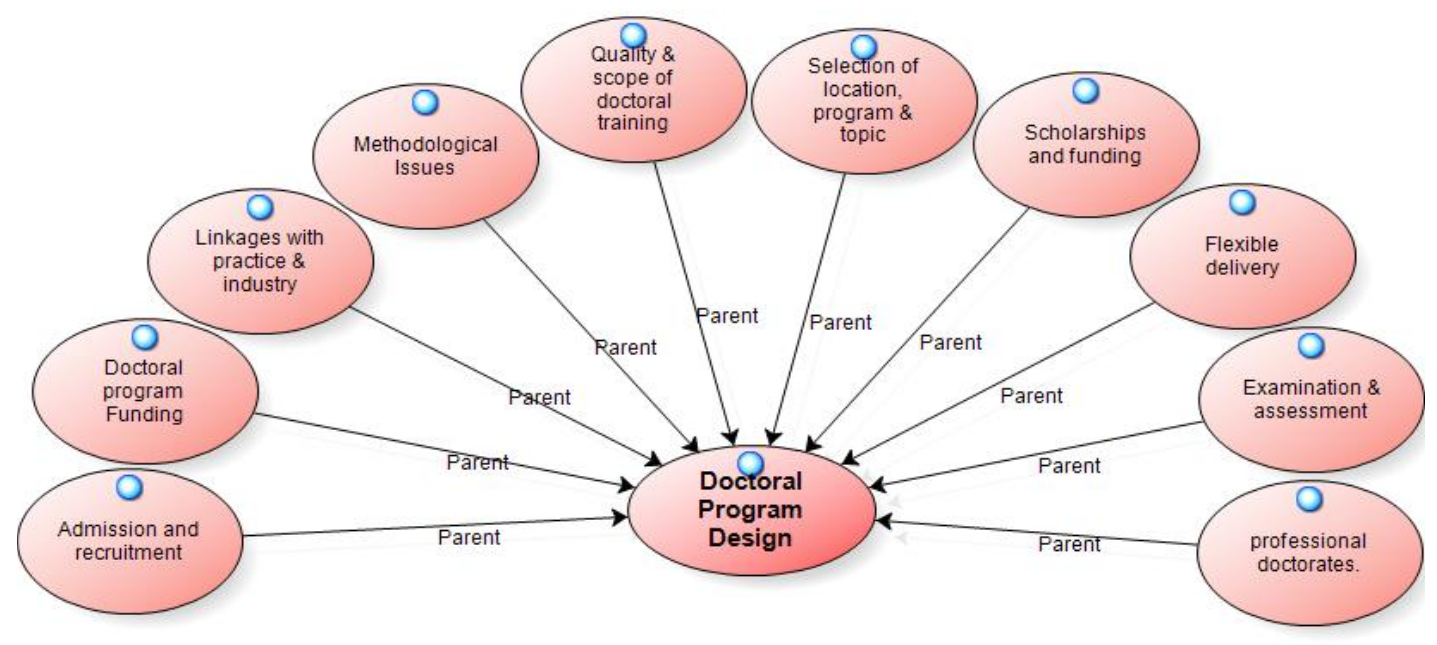

Figure 4: Issues around doctoral program design

\section{Admission and recruitment}

A central theme in this topic area is a mismatch between academic achievements of individual students and the requirements of the doctorate degree. Students are typically accepted into their doctorate as a result of good academic performance. However, independent creative work is a better indicator of match between performance and expectations.

Another thread is the discussion over entry standards which create undersupply or oversupply of doctoral students (according to the economic condition of the time). Here authors argue for a related weakening or strengthening of these entry standards in order to maintain a consistent flow of doctoral students and faculty.

\section{Doctoral program funding}

Doctoral program funding examines the structure of funding as it is received from external bodies into the university to manage doctoral programs. In most cases authors complain about the interference of external guidelines and regulations, and of the omnipresent shortage of funds preventing adequate operations.

\section{Examination \& assessment}

There were several discussions on assessment. These include the following:

- a lack of transparency;

- a lack of consistency across and within countries, and across examiners;

- the examination/thesis is too difficult given today's environment and needs and has reduced appropriateness.

Most authors also speak out against the use of the viva voce pointing to its gross inconsistencies.

\section{Linkages with practice \& industry}

There is a strong (and building) opinion that the doctorate has drifted away from its practical roots, and that the program, the university, and the student can benefit greatly by rebuilding these connections. This general opinion is mirrored by Manathunga et al. (2012, p. 843):

Researchers of the future will need to be able to work across the increasingly porous boundaries between university, industry, government and community sectors. Concerns 
have been raised internationally for several decades about the content and approaches adopted in doctoral programs. Innovative doctoral programs that facilitate students' experiences of industry-based research have been introduced around the globe as one approach to addressing these concerns.

\section{Professional doctorates}

A great deal of discussion has been held on the issue of the professional doctorate. These discussions are on both sides of the issue, with a contingent of authors querying the value of the degree, questioning its merit and place, and the other half stating its value, especially with stronger linkages to industry and its 'terminal' status. A particularly cogent argument for the professional doctorate was with regard to the career choice of the student. This argument points out the use of the $\mathrm{PhD}$ as an entry barrier to academia and its relative futility to a student who has no intention of entering academia.

\section{Issues around Doctoral Writing and Research}

The discussions around writing and research focused on the increasing need for students to write well and publish, and to do so earlier with an increased emphasis on quality. Three of these six sub-topics (Figure 5) contained sufficient volume of publication to warrant additional discussion. These are addressed below.

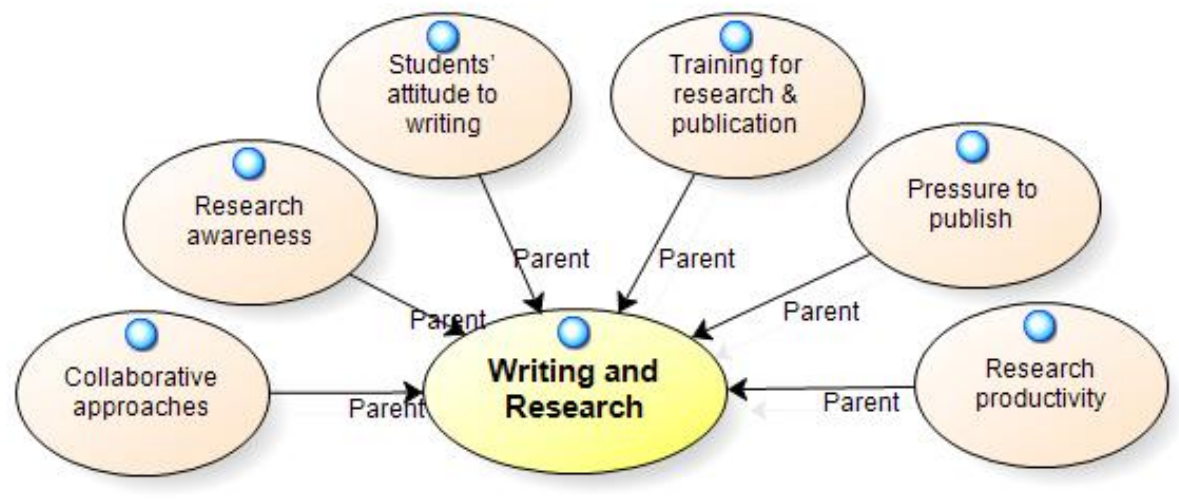

Figure 5: Issues around writing and research

\section{Pressure to publish}

The literature provides no doubt that the competitive 'bar' for doctoral students is rising in terms of both quantity and quality:

In today's academic climate, the old adage "publish or perish" no longer applies solely to postdoctoral scholars, lecturers, visiting and tenure-track faculty members. Many masters and doctoral (graduate) students nationwide are expected to publish their research results before graduation. Many leading academic departments have required their respective master's and doctoral students to publish at least one and two to three research articles in scholarly journals, respectively, as part of their graduation requirements. (Lei \& Chuang, 2009, p. 1163)

The graph in Figure 6 presents the rising curve of expectation, modeling the pressure for doctoral student to publish. 


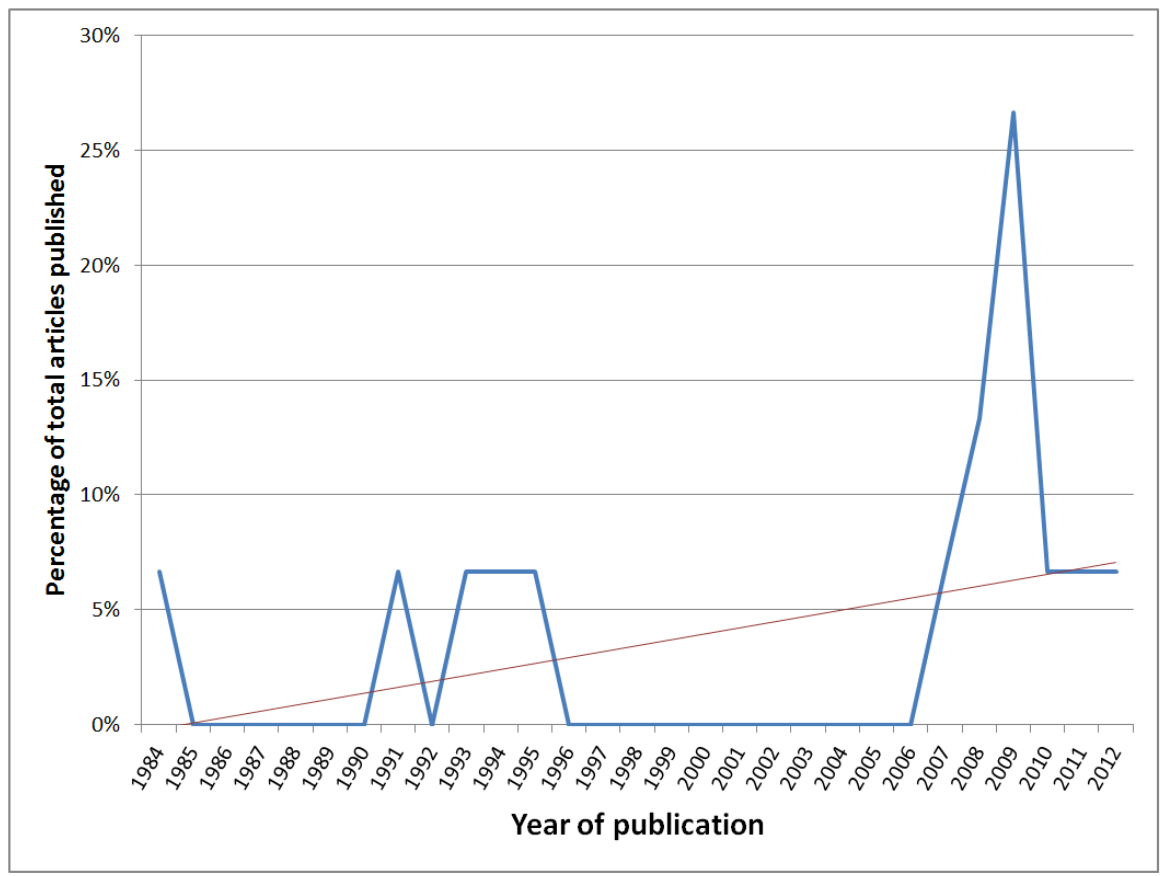

Figure 6: Rising pressure to publish

\section{Collaborative approaches}

There also exists a quantum of articles discussing and recommending the adoption of collaborative approaches to writing and research. The benefits expounded for this are increased productivity and quality, peer support, and socialization. Further, these approaches can increase access to industry and create interdisciplinary exposure.

\section{Research productivity}

Most studies addressing this issue seemed to be trying to solve the conundrum of what variables or antecedents will work best to fine-tune (or select) the most productive members of faculty. A range of variables were tested across several studies. These variables have been classified into four types and are presented in Table 2. (While the studies included in this analysis were studies based on the performance of doctoral students, this issue clearly has broader implications).

Table 2: Variables tested for effect on research productivity

\begin{tabular}{|c|c|c|c|}
\hline Personal & Supervisor & Institution & External \\
\hline $\begin{array}{c}\text { perceptions of supervisor support; } \\
\text { age; behavior; cognition; employ- } \\
\text { ment status; gender; mobility; } \\
\begin{array}{c}\text { number of dependents; affect; quality } \\
\text { of student; race; salary; status of } \\
\text { nationality; writing habits }\end{array}\end{array}$ & $\begin{array}{c}\text { impact of } \\
\text { productivity } \\
\text { of supervisor }\end{array}$ & $\begin{array}{c}\text { proportion of faculty } \\
\text { with PhD's; faculty } \\
\text { research productivity; } \\
\text { departmental } \\
\text { climate; size of faculty }\end{array}$ & $\begin{array}{c}\text { labour } \\
\text { market } \\
\text { strength }\end{array}$ \\
\hline
\end{tabular}

For example, one of the 'personal' variables looked at the role of the 'perceptions of supervisor support' for the doctoral student, and its effect, positive or negative' in creating productivity through research and publication (Platow, 2012). 


\section{Issues around Employment and Career}

This theme can be broken down into seven sub-themes, as presented in Figure 7. There is a lot of discussion on the subject of employment and career, particularly on the topics of 'finding a job' and 'Career advancement'. However, a large amount of this discussion has arisen as a result of the various periods of economic instability over the last forty years. This can be seen in the graph in Figure 8. Both of these are manifestations of the uncertainty and anxiousness resulting from the periods of academic recession (Williams \& Johansen, 1985) as illustrated in Figure 8. Just as authors wrote of their concerns for the placement of $\mathrm{PhD}$ students into work and the consequent shortages of academic staff, so too did these have flow on implications into the long-term careers of PhD's and on the ramifications of obstructions to the flow of fresh recruits into academia.

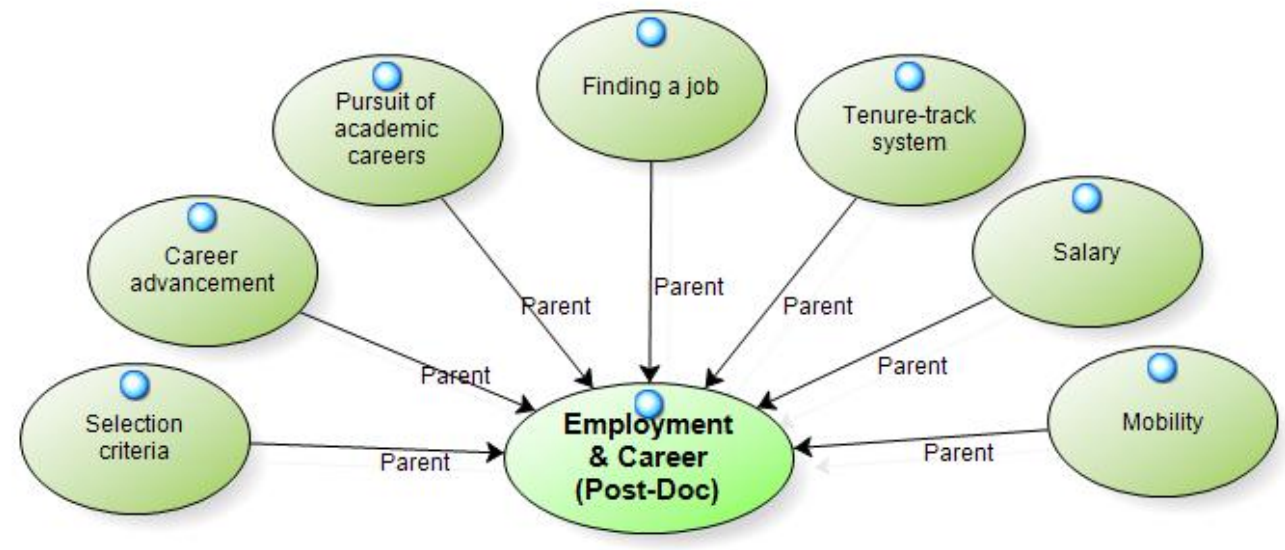

Figure 7: Issues around employment and career

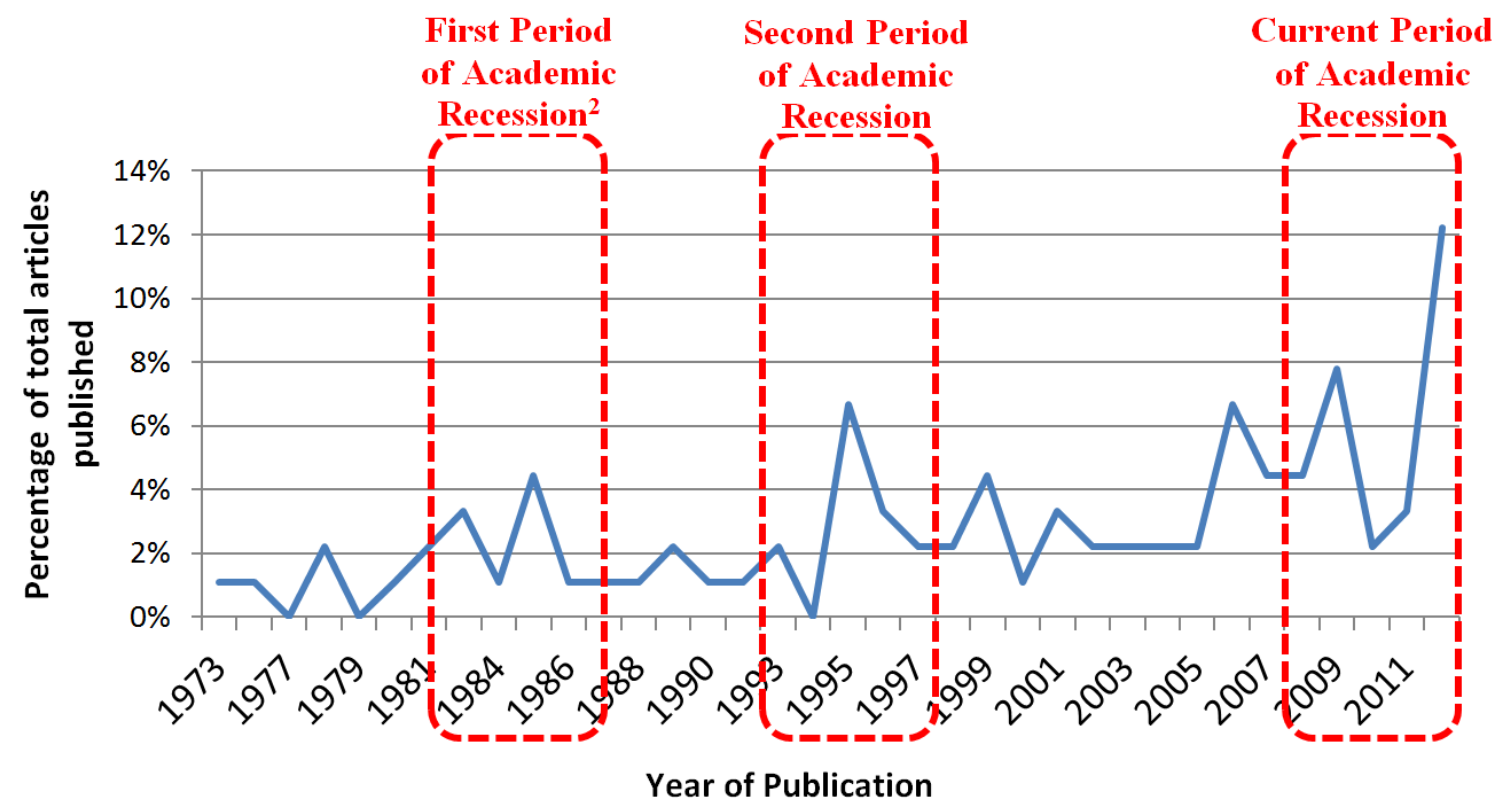

Figure 8: Periods of heightened job and career related publication activity.

This chart has been created from data discussed in Williams \& Johansen (1985).

The time periods represented in boxes with dashed red lines indicate actual periods of time. 


\section{Issues around the Student-Supervisor Relationship}

The relationship between the student and their supervisor is paramount to successful on-time completion. This section of literature discusses the various aspects of this relationship, with issues directly pertinent to the supervisor being the most prominent element of the discussion (see Figure 9). Of the remaining sub-themes 'Student's perceptions of supervisor' is most dominant. These two sub-themes will be discussed in detail below, with some reflection on 'Supervisor perceptions of student' and 'Supervisor-doctoral student interaction'.

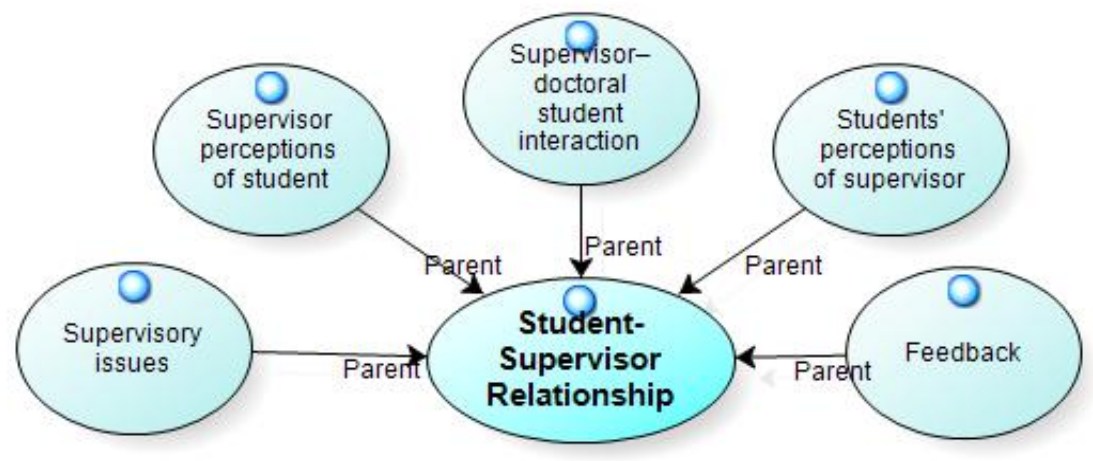

Figure 9: Issues around the student-supervisor relationship

\section{Supervisory issues}

Two main elements contribute to this theme. The first of these - competencies - makes two points. One, that there is a diminution in supervisory capabilities in most doctoral supervisors today, and while academics have strengthened their abilities to write and publish, they have largely overlooked this fundamental role of mentorship. Further, there is a lack of suitable training available to fill the void. Second, that there is a list of competencies that supervisors can gain, strengthen, and be measured by. Hyatt and Williams (2011, p. 58-60) provide a very good list of competencies based on their research into the issue. Their factors include the following:

Teaching role competencies

1. Communication and facilitation skills

2. Familiarity with theory and practice

3. Use of technology

4. Modeling and teaching ethics

5. Knowledge of and experience with organizational trends

6. Pedagogical understanding

7. Modeling lifelong learning

Advising role competencies

1. Knowledgeable about research methods, tools, and technologies

2. Guide quality written work

3. Availability to students

4. Student Engagement (as co-researchers)

5. Coaching skills

6. Responsible for dissertation advisement

7. Teaching of research ethics $\underline{\text { Research role competencies }}$

1. Able to view issues from multiple perspectives 2. Understand the role of faculty research in teaching and learning

3. Continuous development of scholarly skills

4. Innovative and adaptive

5. Contribute to the field through publications and presentations

6 . Understand and promote the role of faculty research to increase program and university prestige

7. Use of technology for research

$\underline{\text { Service role competencies }}$

1. Team and collaboration skills

2 . Active in university and professional communities

3. Consultancy skills

4. Ability to work with diverse groups

5. Use of technological skills for service

6. Support the University mission

7. Active in the broader community 
Colleagueship role competencies

1. Accept and value others

2. Good interpersonal skills

3. Encouragement of diverse thinking

4. A mentor and servant leader
5. Knowledge and support of the program mission and goals

6. Use of technology for collaboration

7. Understanding of the culture and politics of the university, college/school, and department

Note: these factors are adopted directly from Hyatt \& Williams (2011) with the exception that the language has been adjusted in several instances to make each part more consistent with the whole.

The second element - Group supervision - looks at making improvements to the supervision experience by aligning groups of students with groups of supervisors, and so subordinating the direct one-to-one relationship. The strengths of this approach promise increased socialization and supervisory leadership and support, and in some cases, strengthened cross-disciplinary coverage.

\section{Student's perceptions of supervisor}

The remaining factors are branches of the same tree. While most discussion in articles concerns the student's view of the relationship, these sibling elements of 'Supervisor perceptions of student', 'Supervisor-doctoral student interaction' and 'Student-Supervisor Relationship' have a similar type of influence on the progress and success of a doctoral student. The reason that this primary factor (student's perception) is more important is because perception is reality. The supervisory relationship is likely to make or break the doctoral candidature. A poor relationship with one's doctoral advisor will ruin a good doctoral project regardless of any or all of the other elements which may support it. Therefore, a lot of research and discussion has gone into understanding this relationship, and seeking to improve it, or at least failsafe it. An associated area which receives a lot of empirical attention looks at the factors which lead to selection of a student's 'ideal' supervisor.

\section{Issues around the Doctoral Student Experience}

This final theme is a large and very important area of discussion in doctoral studies literature. The process of undertaking a $\mathrm{PhD}$ is (it is now clear to me) quite harrowing. Students suffer from discrimination and many inequities. Students undergo hardships through isolation, alienation, and loneliness. Students are resource and relationship poor and require financial support, peer support, family support, employer support, and faculty support. Students have a host of individual development issues and challenges including a need for autonomy, a quest for competence and identity, an appeal for independence, and a weakness for time management. Students must navigate through a comprehensive collection of cultural challenges like departmental culture, disciplinary culture, individual culture, and institutional culture. On top of this there are two even more burning issues doctoral students must confront. One is the socialization processes, and the other is dissertation progress. In addition, the topic of discrimination and equity deserves a closer look. These three subthemes will be explored in more detail below. Figure 10 illustrates the complexity of this theme. 


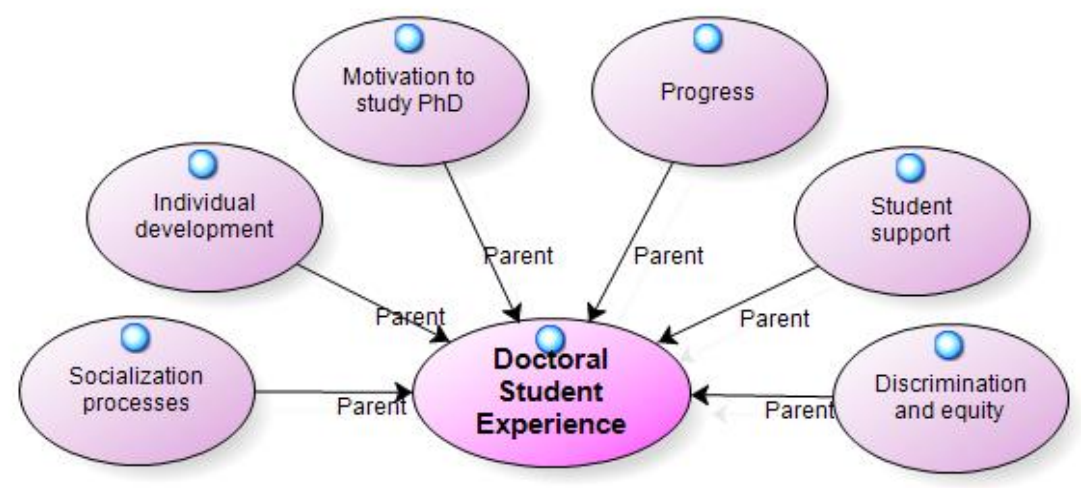

Figure 10: Issues around the doctoral student experience

\section{Socialization processes}

Socialization has been found to be a "determining factor in doctoral student success and retention" (Gardner, 2008, p. 125). The socialization process that doctoral students undergo is important for a number of reasons. First, through peer contact it helps to dissolve boundaries and reduce feelings of isolation. Second, socialization helps students to prepare for their current and future environments by learning the rules and culture of their discipline and by acquiring the knowledge and skills, values and attitudes, and habits and thoughts of the society they wish to enter (Bragg, 1976). Golde (1998) finds that the socialization of doctoral students achieves four tasks; these are presented in Table 3.

Table 3: The four tasks of socialization in doctoral students (Golde, 1998)

\begin{tabular}{|ccc|}
\hline Task & Achievement & Question answered \\
\hline Intellectual mastery & Intellectual Competence & "Can I do this?" \\
\hline Realities of graduate life & $\begin{array}{c}\text { Fitting in and } \\
\text { surviving the struggle }\end{array}$ & $\begin{array}{c}\text { "Do I want to be a } \\
\text { graduate student?" }\end{array}$ \\
\hline Professional preparation & $\begin{array}{c}\text { Clarification of } \\
\text { career choice }\end{array}$ & $\begin{array}{c}\text { "Do I want to } \\
\text { do this work?" }\end{array}$ \\
\hline Departmental integration & $\begin{array}{c}\text { Career-life fit } \\
\text { and balance }\end{array}$ & "Do I belong here?" \\
\hline
\end{tabular}

\section{Progress}

The issue of progress concerns itself with those elements which work to impede successful doctoral completion. Progress comprises four major sub-themes; these are 'Time to completion', 'Attrition and retention', 'Stress, exhaustion \& anxiety', and 'Student-life balance'. Research on time to completion, attrition, and retention largely relate to trying to understand the factors which impact on these elements and ultimately on doctoral success. A lot of the literature also works to highlight the problems around retention and completion, raising awareness of poor completion rates. Discussions on stress, exhaustion, $\&$ anxiety look at the factors that contribute to these issues for doctoral students and reinforcing the need for the final factor - student-life balance which looks at various coping strategies used by doctoral students. 


\section{Discrimination and equity}

Discussions on discrimination and equity are mostly about equality for blacks and for females. While some of these papers report an achievement of equity, the vast majority complain about a lack of equality. What is interesting about this topic is the countries which enter into the debate. As can be seen in Figures 11 and 12, the United States is far more concerned with issues of discrimination and equity than is any other country.

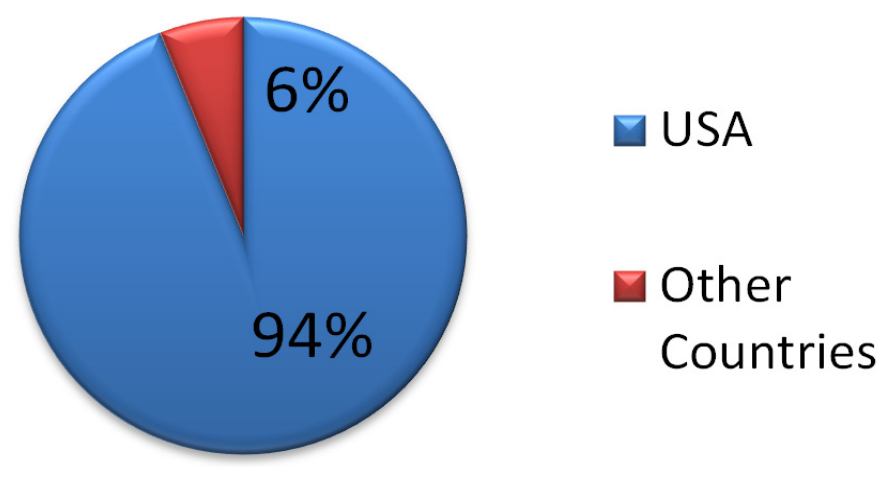

Figure 11: Publications discussing racial discrimination according to country

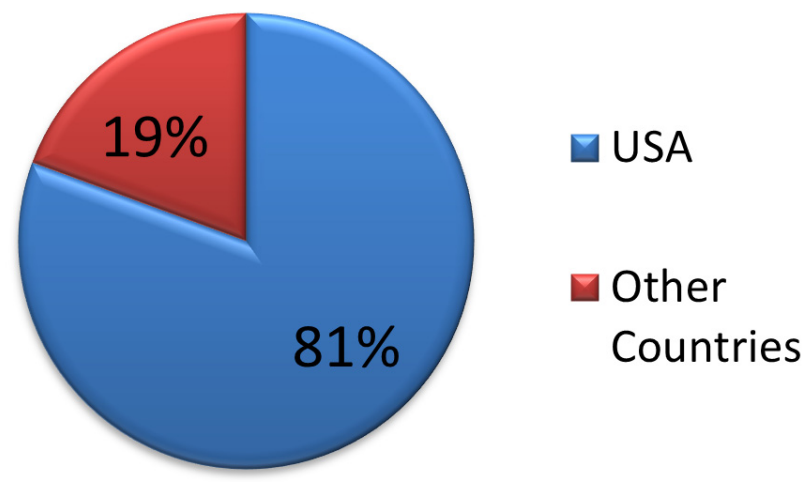

Figure 12: Publications discussing gender discrimination according to country

The next section of this paper will present a discussion based on this analysis, commencing with a look at the dispersion of data across chronological and geographical lines. Following this, the paper will conclude with a discussion on areas for further development in the area of doctoral studies.

\section{Discussion}

The analysis and findings in the preceding section presented the themes of discussion that can be found in the body of knowledge in journals publishing doctoral studies. This section will now look at this body of knowledge as a whole to discover its characteristics, specifically, where are these articles coming from, and over what periods of time. The following sections will delve more deeply into these characteristics. 
Figure 13 shows the breakdown of total publications according to year. It is perhaps not surprising to discover that the US, Australia, UK and Canada dominate the publications. Doctoral programs have been active in these countries for a longer period of time, and as such the range of discussion was not only more abundant, but also more sophisticated, exploring more subtle issues of the doctoral journey. Table 4 presents the entire data, with values for all countries.

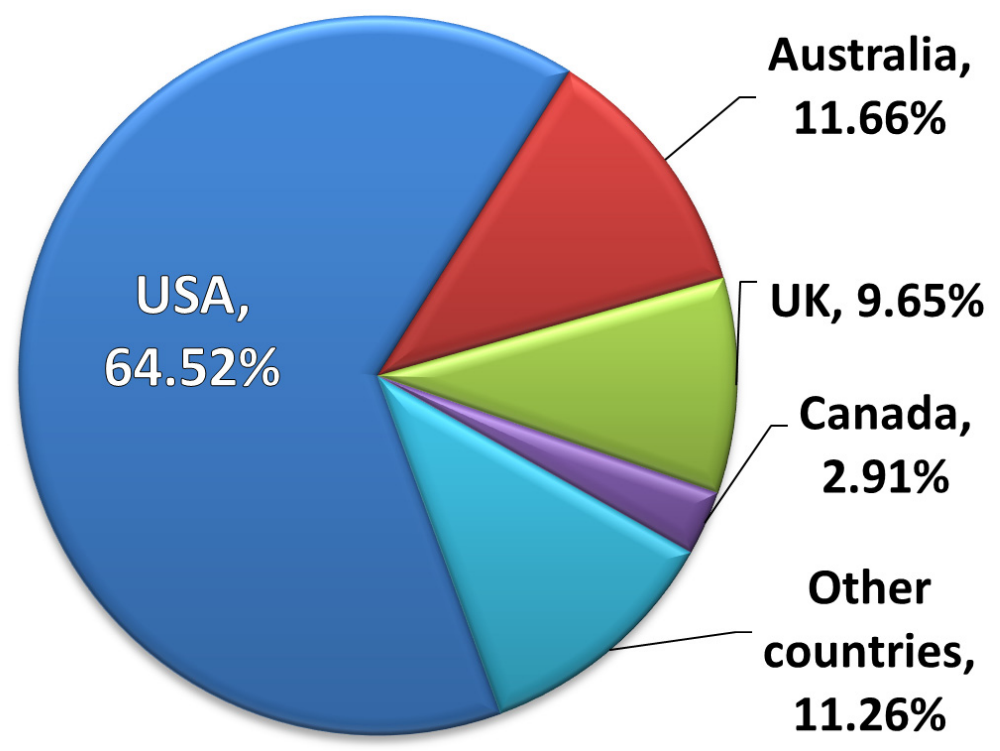

Figure 13: Distribution of doctoral articles by country of author

Table 4: Breakdown of publications by country

\begin{tabular}{|c|c|c|c|c|c|}
\hline $\begin{array}{l}\text { Author } \\
\text { Country }\end{array}$ & $\begin{array}{l}\text { Percentage of } \\
\text { publications }\end{array}$ & $\begin{array}{l}\text { Author } \\
\text { Country }\end{array}$ & $\begin{array}{l}\text { Percentage of } \\
\text { publications }\end{array}$ & $\begin{array}{l}\text { Author } \\
\text { Country }\end{array}$ & $\begin{array}{l}\text { Percentage of } \\
\text { publications }\end{array}$ \\
\hline Australia & $11.66 \%$ & Hong Kong & $0.20 \%$ & Pakistan & $0.20 \%$ \\
\hline Austria & $0.30 \%$ & India & $0.10 \%$ & Poland & $0.10 \%$ \\
\hline Belgium & $0.20 \%$ & Iran & $0.20 \%$ & Portugal & $0.30 \%$ \\
\hline Botswana & $0.10 \%$ & Ireland & $0.30 \%$ & Romania & $0.10 \%$ \\
\hline Canada & $2.91 \%$ & Israel & $0.30 \%$ & Singapore & $0.10 \%$ \\
\hline China & $0.30 \%$ & Italy & $0.10 \%$ & South Africa & $0.60 \%$ \\
\hline Denmark & $0.10 \%$ & Japan & $0.20 \%$ & Spain & $0.30 \%$ \\
\hline Estonia & $0.10 \%$ & Kenya & $0.10 \%$ & Sweden & $1.11 \%$ \\
\hline Europe & $0.90 \%$ & Korea & $0.10 \%$ & Switzerland & $0.20 \%$ \\
\hline Finland & $1.31 \%$ & Netherlands & $0.50 \%$ & Taiwan & $0.30 \%$ \\
\hline France & $0.20 \%$ & New Zealand & $1.01 \%$ & UK & $9.65 \%$ \\
\hline Germany & $1.01 \%$ & Norway & $0.50 \%$ & USA & $64.52 \%$ \\
\hline
\end{tabular}

An interrogation of the data according to year of publication reveals a rapid escalation in growth of publications over time. Figure 14 illustrates this. 


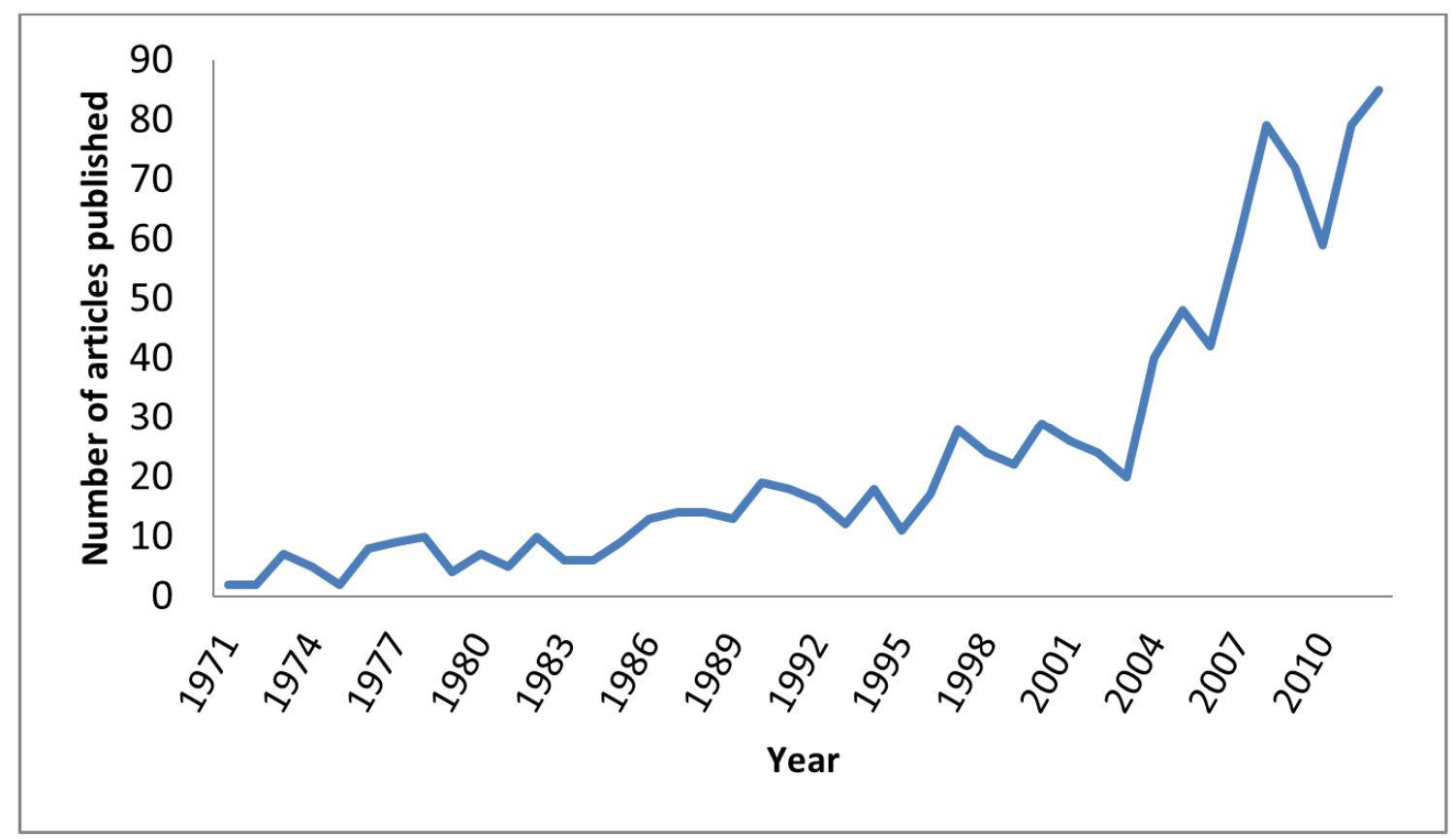

Figure 14: Distribution of doctoral articles by year of publication

The next graph, Figure 15, couples these two dimensions together. However, as the number of countries is too large to produce a country-by-country breakdown, the countries have been classified and sorted according to their Human Development Index (HDI). The HDI is produced annually by United Nations Development Program (www.undp.org). It scores countries according to three dimensions: health, education, and income. Health is based on life expectancy at birth. Education is based on expected years of schooling and mean years of schooling. Income is based on gross national income per capita (PPP). The index can be used as a means of comparing countries according to their preparedness for education, their priority on education, and there propensity for investment in tertiary education. Tables 5 to 8 show the allocated HDI score for countries publishing in doctoral journals.

Table 5: HDI Scores - top 5 ranked countries.

\begin{tabular}{|l|c|}
\hline Country & Score \\
\hline Australia & 2 \\
\hline Netherlands & 3 \\
\hline New Zealand & 5 \\
\hline Norway & 1 \\
\hline USA & 4 \\
\hline
\end{tabular}

Table 6: HDI Scores - next 10 ranked countries.

\begin{tabular}{|l|c|c|l|c|}
\hline Country & Score & & Country & Score \\
\hline Canada & 6 & & Japan & 12 \\
\hline China & 13 & & Korea & 15 \\
\hline Germany & 9 & Sweden & 10 \\
\hline Hong Kong & 13 & & Switzerland & 11 \\
\hline Ireland & 7 & & Taiwan & 13 \\
\hline
\end{tabular}


Table 7: HDI Scores - next 30 ranked countries.

(Note: only 13 countries are represented here. The remaining 17 countries are yet to make a contribution to the doctoral literature, and thus do not appear in this analysis)

\begin{tabular}{|c|c|c|c|}
\hline Country & Score & Country & Score \\
\hline Austria & 19 & Italy & 24 \\
\hline Belgium & 18 & Poland & 39 \\
\hline Denmark & 16 & Portugal & 41 \\
\hline Estonia & 34 & Singapore & 26 \\
\hline Finland & 22 & Spain & 23 \\
\hline France & 20 & UK & 28 \\
\hline Israel & 17 & & \\
\hline
\end{tabular}

Table 8: HDI Scores - remaining ranked countries.

\begin{tabular}{|l|r|}
\hline Country & Score \\
\hline Botswana & 118 \\
\hline India & 134 \\
\hline Iran & 88 \\
\hline Kenya & 143 \\
\hline Pakistan & 145 \\
\hline Romania & 50 \\
\hline South Africa & 123 \\
\hline
\end{tabular}

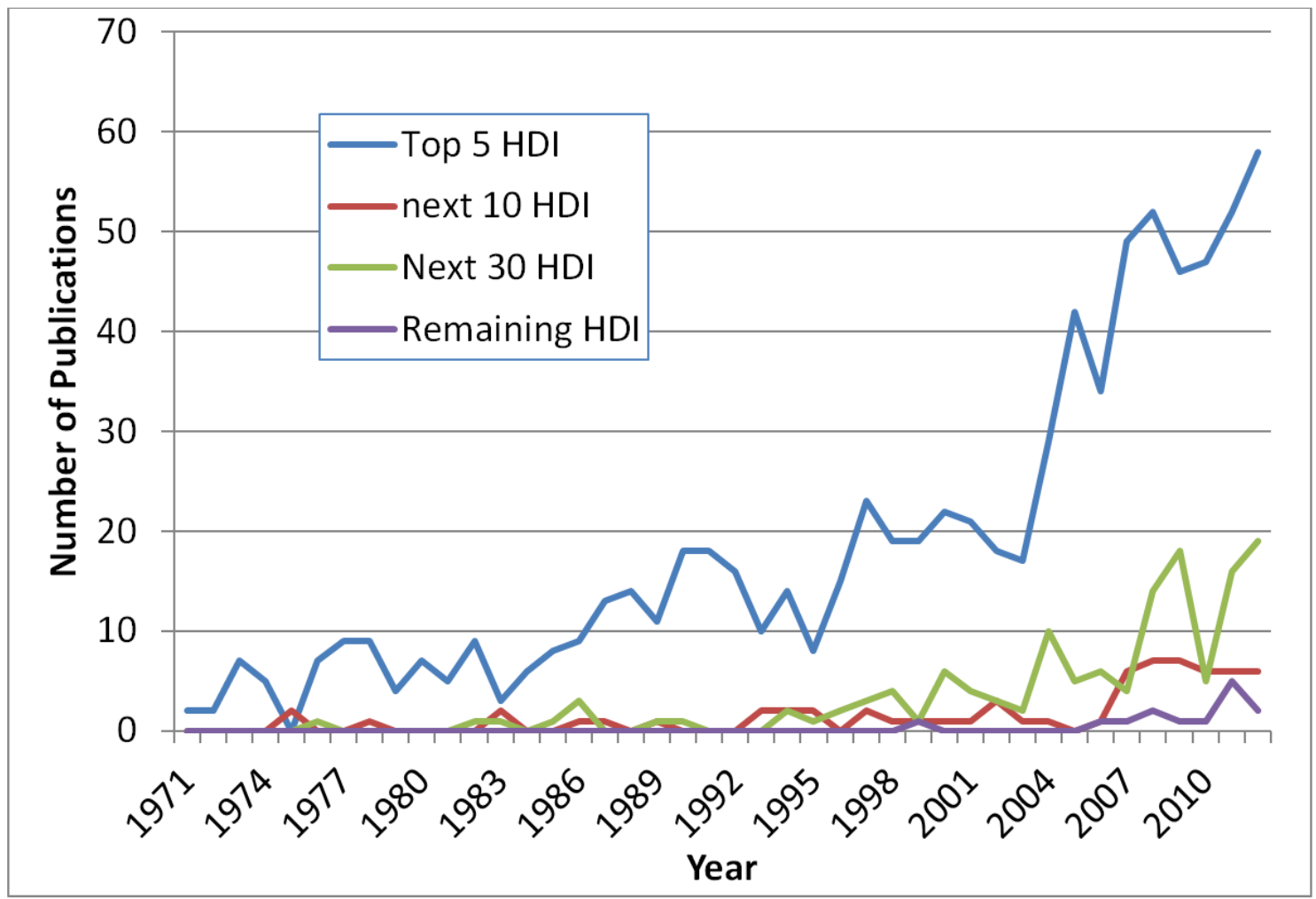

Figure 15: Distribution of doctoral articles by year of publication clustered into HDI countries 
This analysis shows that the more educationally advanced the country is, the more it will engage in debate and research regarding doctoral studies. One surprise here is the 'next 30 HDI' countries outperforming the 'next 10 HDI' countries. The reason for this is that the UK ranks $28^{\text {th }}$ in terms of HDI, yet as we can see in Figure 13, the UK represents almost one tenth of all publications in this area.

Discussion on issues in doctoral education is a growing domain. As lower ranked HDI countries continue to develop an educational agenda so too will their contributions to this field grow. The consequences for this growth will be increased competition for publication in existing journals, which will see an increase in publication quality. Vacancies also exist for the creation of new journals in this field. The next section will conclude this paper by summing up the findings and by reintroducing relevant areas of discussion and research which have been left behind but present appropriate areas for new dialogue.

\section{Conclusion and Further Research}

An understanding of what works, and what does not, in training and developing doctoral students is important, as these students are essential to the continuance of all tertiary educational programs in all countries. Doctoral students are also the potential backbone of all research programs and, as such, are instrumental in the discovery and implementation of new knowledge. Journals such as Higher Education, Studies in Higher Education, and the International Journal of Doctoral Studies lay the foreground for discussion on issues around supporting our doctoral students; without forums of advice such as these journals, academic advisors and their institutions would be struggling to grasp the fundamentals of developing and refining their own doctoral programs. This paper has evaluated this body of knowledge in its entirety. It has analyzed 995 papers across 45 of the most prominent journals publishing in the area of doctoral studies.

The body of knowledge on doctoral studies can be categorized according to six predominant themes. Teaching focuses on ensuring that teaching is an important part of the academic's professional life and, therefore, that there is adequate preparation for doctoral students to become teachers. Discussions on Doctoral program design tend to focus on improving and refining the doctoral program to ensure optimum admission, fair assessment, and stronger industry alignment. Doctoral writing and research literature addressed the issue according to two arguments. One was the increased need for, and pressure to, write and publish more, with an acknowledgment of the increases in both quality and quantity. The other argument was for an increase in collaborative designs to increase efficiencies and to widen access to industry and to cross-disciplinary content. The issues on employment and career tended to be reactionary discussions focusing on temporal issues of over- or under-supply of doctoral students and their consequent employment in the industry. The student-supervisor relationship looked at elements which work to ensure an optimum relationship between the student and their supervisor. The importance of this relationship is widely acknowledged. The final thematic element - the doctoral student experience - discusses the impact on progress and completion of a student's experience during the $\mathrm{PhD}$ program. Student socialization is the key to a positive experience and is most influential in positive outcomes of the $\mathrm{PhD}$.

A secondary analysis of the literature helps to characterize this body of knowledge according to the country and year of publication. This finds that the top HDI countries publish more than other countries, and this is mainly because doctoral programs in these countries are more mature given credence to a host of related discussions related to program improvement. A final observation finds that publications based on doctoral research and discussion are growing at an accelerated rate. The publication vehicles currently available will face capacity strains leading to a sharp increase in journal and article quality and in the birth of a new generation of journals in this field. 


\section{Areas for Further Research}

Analysis of the literature highlights many occurrences of issues which have been raised and established, but which seem to have been prematurely neglected. Many of these early terminated issues warrant further examination and discussion. Four of these will be discussed below.

\section{Research awareness}

Some research has found that doctoral student productivity and cultural fit can be improved by modeling behaviors. One such technique is for a greater awareness of the supervisor (and faculties) research in terms of volume, quality, content, and style. It is thought that greater familiarity with this content will have positive modeling implications on the doctoral students who may feel a compulsion to emulate their superiors. More research, particularly empirical work, is needed to fully explore this phenomenon.

\section{Group supervision}

The traditional supervision model is dyadic. There is emerging research which suggests that an alternative model may have benefits. Such an alternative is based on group supervision or cohortbased pedagogies (Fenge 2012). The benefits of this rather radical approach have not been fully appraised. There is, therefore, scope for universities to experiment with this design and for researchers to evaluate the potential.

\section{Supervisors perceptions of their student}

A lot has been said of the impact that a student's perception of his or her supervisor will have on the student's progress and completion. However, the counter view has barely been discussed. The literature confirms the importance of a good supervisor; it discusses selection criteria that students can use to screen their supervisors for best choice. Therefore, given the clear importance of the supervisor, one must speculate that if the supervisor has a poor perception of the student, then the supervisor's heart and mind may not be invested in the relationship. The supervisor in this situation is not operating at his or her optimum level, as he or she not as fully engaged as he or she could be. More research could be conducted to understand the implications of this scenario, and to explore possible strategies to either prevent it from occurring, or dealing with it if it does arise.

\section{Feedback}

Research has only lightly touched the area of feedback and the implications these have on student performance. The research that does exist tends to focus on supervisory feedback. More research can be invested to discover the influence of the feedback, especially with regard to its delivery, its timing, and its style. The focus of this research could be on expanding existing findings with regard to supervisory feedback. However, real value may be found in investigating the effects of feedback from a variety of sources including family, peers and doctoral colleagues.

\section{Acknowledgements}

I would like to thank my research assistant, Dr. Yoke Berry, for her tireless efforts in scouring through thousands of papers, in a very short period of time, in order for her find the 995 articles which were analyzed here. 


\section{References}

Ali, A.,\& Kohun, F. (2007). Dealing with social isolation to minimize doctoral attrition - A four stage framework. International Journal of Doctoral Studies, 2, 33-49. Retrieved from http://www.ijds.org/Volume2/IJDSv2p033-049Ali28.pdf

Ampaw, F. D., \& Jaeger, A. J. (2012). Completing the three stages of doctoral education: An event history analysis. Research in Higher Education, 53(6), 640-660.

Barnes, B. J. (2010). The nature of exemplary doctoral advisors' expectations and the ways they may influence doctoral persistence. Journal of College Student Retention: Research, Theory \& Practice, $11(3), 323-343$.

Barnes, B. J., \& Austin, A. E. (2009). The role of doctoral advisors: A look at advising from the advisor's perspective. Innovative Higher Education, 33(5), 297-315.

Barnes, B. J., Williams, E. A., \& Archer, S. A. (2010). Characteristics that matter most: Doctoral students' perceptions of positive and negative advisor attributes. NACADA Journal, 30(1), 34-46.

Boyatzis, R. E. (1998). Transforming qualitative information: Thematic analysis and code development. Thousand Oaks, CA: Sage Publications.

Bragg, A. K. (1976). The socialization process in higher education. Washington, DC: The George Washington University.

Braun, V., \& Clarke, V. (2006). Using thematic analysis in psychology. Qualitative Research in Psychology, 3(2), 77-101.

Davis, H., Evans, T., \& Hickey, C. (2006). A knowledge-based economy landscape: Implications for tertiary education and research training in Australia. Journal of Higher Education Policy and Management, 28(3), 231-244.

Delamont, S., Atkinson, P., \& Parry, O. (1997). Critical mass and doctoral research: Reflections on the Harris Report. Studies in Higher Education, 22(3), 319-331.

Felt, U., Igelsböck, J., Schikowitz, A., \& Völker, T. (2012). Growing into what? The (un-)disciplined socialisation of early stage researchers in transdisciplinary research. Higher Education, 1-14.

Fenge, L. A. (2012). Enhancing the doctoral journey: The role of group supervision in supporting collaborative learning and creativity. Studies in Higher Education, 37(4), 401-414.

Gaff, J. G., \& Pruitt-Logan, A. S. (1998). Preparing college faculty. New Directions for Higher Education, $101,77-86$.

Gardner, S. K. (2008). Fitting the mold of graduate school: A qualitative study of socialization in doctoral education. Innovative Higher Education, 33(2), 125-138.

Gardner, S. K. (2010). Faculty perspectives on doctoral student socialization in five disciplines. International Journal of Doctoral Studies, 5, 39-53. Retrieved from http://ijds.org/Volume5/IJDSv5p039-053Gardner293.pdf

Gardner, S. K., \& Gopaul, B. (2012). The part-time doctoral student experience. International Journal of Doctoral Studies, 7, 63-78. Retrieved from http://ijds.org/Volume7/IJDSv7p063-078Gardner352.pdf

Geertz, C. (1973). The interpretation of cultures: Selected essays. New York: Basic Books.

Golde, C. M. (1998). Beginning graduate school: Explaining first-year doctoral attrition. New Directions for Higher Education, 101, 55-64.

Halse, C. (2011). 'Becoming a supervisor': The impact of doctoral supervision on supervisors' learning. Studies in Higher Education, 36(5), 557-570.

Halse, C., \& Malfroy, J. (2010). Retheorizing doctoral supervision as professional work. Studies in Higher Education, 35(1), 79-92. 
Hyatt, L., \& Williams, P. E. (2011). 21st Century competencies for doctoral leadership faculty. Innovative Higher Education, 36(1), 53-66.

Ivankova, N. V., \& Stick, S. L. (2007). Students' persistence in a distributed doctoral program in educational leadership in higher education: A mixed methods study. Research in Higher Education, 48(1), 93-135.

Jairam, D., \& Kahl Jr, D. H. (2012). Navigating the doctoral experience: The role of social support in successful degree completion. International Journal of Doctoral Studies, 7, 311-329. Retrieved from http://ijds.org/Volume7/IJDSv7p311-329Jairam0369.pdf

Jepsen, D. M., Varhegyi, M. M., \& Edwards, D. (2012). Academics' attitudes towards PhD students' teaching: Preparing research higher degree students for an academic career. Journal of Higher Education Policy and Management, 34(6), 629-645.

Jiranek, V. (2010). Potential predictors of timely completion among dissertation research students at an Australian faculty of sciences. International Journal of Doctoral Studies, 5, 1-13. Retrieved from http://ijds.org/Volume5/IJDSv5p001-013Jiranek273.pdf

Jones, M., \& Alony, I. (2011). Guiding the use of grounded theory in doctoral studies-An example from the Australian film industry. International Journal of Doctoral Studies, 6, 95-114. Retrieved from http://ijds.org/Volume6/IJDSv6p095-114Jones322.pdf

Kim, D., \& Otts, C. (2010). The effect of loans on time to doctorate degree: Differences by race/ethnicity, field of study, and institutional characteristics. Journal of Higher Education, 81(1), 1-32.

Lei, S. A., \& Chuang, N.-K. (2009). Research collaboration and publication during graduate studies: Evaluating benefits and costs from students' perspectives. College Student Journal, 43(4), 1163-1168.

Lott, J. L., Gardner, S., \& Powers, D. A. (2010). Doctoral student attrition in the STEM fields: An exploratory event history analysis. Journal of College Student Retention: Research, Theory \& Practice, 11(2), 247-266.

Manathunga, C., Pitt, R., Cox, L., Boreham, P., Mellick, G., \& Lant, P. (2012). Evaluating industry-based doctoral research programs: Perspectives and outcomes of Australian Cooperative Research Centre graduates. Studies in Higher Education, 37(7), 843-858.

McAlpine, L., \& Amundsen, C. (2012). Challenging the taken-for-granted: How research analysis might inform pedagogical practices and institutional policies related to doctoral education. Studies in Higher Education, 37(6), 683-694.

Millett, C. M., \& Nettles, M. T. (2006). Expanding and cultivating the Hispanic STEM doctoral workforce: Research on doctoral student experiences. Journal of Hispanic Higher Education, 5(3), 258-287.

Park, C. (2005). New variant PhD: The changing nature of the doctorate in the UK. Journal of Higher Education Policy and Management, 27(2), 189-207.

Platow, M. J. (2012). PhD experience and subsequent outcomes: A look at self-perceptions of acquired graduate attributes and supervisor support. Studies in Higher Education, 37(1), 103-118.

Rice, P. L., \& Ezzy, D. (1999). Qualitative research methods: A health focus. Melbourne: Oxford University Press.

Thune, T. (2009). Doctoral students on the university-industry interface: A review of the literature. Higher Education, 58(5), 637-651.

Williams, J. E., \& Johansen, E. (1985). Career disruption in higher education. Journal of Higher Education, $56(2), 144-160$.

Yardley, L., \& Marks, D. F. (2004). Research methods for clinical and health psychology. London Sage Publications Limited. 


\section{Biography}

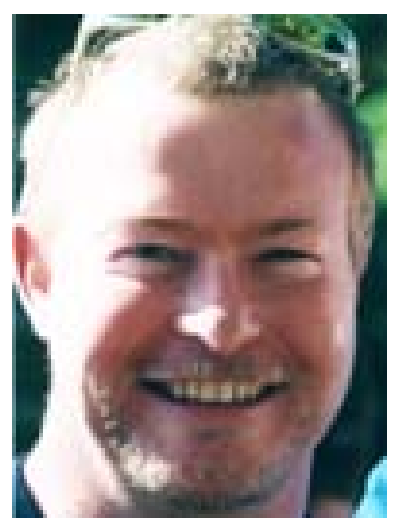

Michael Jones (BComm (hons), $\mathrm{PhD}$.) has been an academic teaching and researching in areas of organization, business and management for ten years. Michael has developed research interests in the following areas: organizational psychology and behavior - looking at commitment and motivation and group dynamics. Michael also has research strengths in areas of qualitative analysis and has written several papers on various qualitative methodologies and methods. Michael is interested in research areas such as doctoral studies, organizational culture, and motivation and commitment. Michael is a co-investigator on a major research project exploring retention and engagement in Emergency Management Agencies.

Michael is a member of the Australia and New Zealand Academy of Management, the Australian Human Resources Institute, and the Industrial Relations Society of Australia. 


\section{Appendix - Distribution of sources used ${ }^{1}$}

\begin{tabular}{|c|c|c|}
\hline Journal Name & $\begin{array}{l}\text { Number of } \\
\text { matching } \\
\text { sources }\end{array}$ & $\begin{array}{l}\text { Journal } \\
\text { Quality } \\
\text { (ERA 2010) }^{3}\end{array}$ \\
\hline Academe & 24 & c \\
\hline Academy of Management Learning \& Education & 9 & $A^{*}$ \\
\hline American Educational Research Journal & 3 & $\mathrm{~A}^{*}$ \\
\hline Assessment \& Evaluation in Higher Education & 7 & A \\
\hline Black Issues in Higher Education & 50 & Not Ranked \\
\hline British Journal of Educational Technology & 3 & A \\
\hline Canadian Journal of Educational Administration and Policy & 1 & C \\
\hline Canadian Journal of Higher Education & 12 & C \\
\hline Chronicle of Higher Education & 84 & Not Ranked \\
\hline College Student Journal & 22 & C \\
\hline Counselor Education and Supervision & 68 & $\mathrm{c}$ \\
\hline Education \& Training & 2 & $A^{*}$ \\
\hline Educational Researcher & 24 & $A^{*}$ \\
\hline Educational Studies & 3 & C \\
\hline European Journal of Education & 19 & B \\
\hline Gender and Education & 10 & B \\
\hline Harvard Educational Review & 9 & $\mathrm{~A}^{*}$ \\
\hline Higher Education & 102 & $A^{*}$ \\
\hline Higher Education in Europe & 14 & A \\
\hline Higher Education Management and Policy & 3 & C \\
\hline Higher Education Research and Development & 30 & A \\
\hline Improving College and University Teaching & 11 & Not Ranked \\
\hline Innovative Higher Education & 28 & B \\
\hline International Journal for Academic Development & 8 & B \\
\hline International Journal of Doctoral Studies & 30 & B \\
\hline Internet and Higher Education & 11 & B \\
\hline Journal of College Student Development & 19 & C \\
\hline Journal of College StudentRetention: Research. Theory \& Practice & 6 & C \\
\hline Journal of Educational Administration & 10 & C \\
\hline Journal of Further and Higher Education & 12 & B \\
\hline Journal of Higher Education Policy and Management & 21 & B \\
\hline Journal of Hispanic Higher Education & 8 & C \\
\hline Journal of Negro Education & 5 & C \\
\hline Journal of StudentAffairs Research and Practice & 2 & Not Ranked \\
\hline NACADA Journal & 5 & C \\
\hline NASPA Journal & 11 & c \\
\hline New Directions for Higher Education & 22 & Not Ranked \\
\hline Quality in Higher Education & 3 & A \\
\hline Research in Higher Education & 108 & A \\
\hline Review of Educational Research & 3 & $A^{*}$ \\
\hline Review of Higher Education & 21 & B \\
\hline Scandinavian Journal of Educational Research & 13 & B \\
\hline Studies in Continuing Education & 21 & A \\
\hline Studies in Higher Education & 68 & $A^{*}$ \\
\hline Teaching in Higher Education & 31 & A \\
\hline \multirow[t]{2}{*}{ Other } & 19 & N/A \\
\hline & 995 & \\
\hline
\end{tabular}

\footnotetext{
${ }^{1}$ ERA 2010 is the system of quality and impact assessment of journals adopted by the Australian Government
} 